\title{
Blood pressure, heart rate, and rate pressure product behavior during interval and continuous aerobic exercise \\ Comportamiento de la presión arterial, frecuencia cardíaca y doble producto durante el ejercicio aeróbico a intervalos y continuo
}

\author{
*,***Victor Gonçalves Corrêa Neto, *Juliana Augusto do Rosário, ****Nathaniel Bodell, **Gleisson da Silva Araújo, \\ **,***Luiz Guilherme da Silva Telles, *****Jeter Pereira de Freitas, ***.*****,*****Marcelo José C. Miranda Colonna, \\ **Jefferson da Silva Novaes, *,***,******Felipe da Silva Triani, *******Rudson Santos da Silva, **,*****Estêvão Rios \\ Monteiro \\ *Gama e Souza University Center (Brazil), **Federal University of Rio De Janeiro (Brazil), ***Estácio de Sá University (Brazil), \\ ****California State University (USA.), $* * * * *$ Augusto Motta University Center (Brazil), ******Rio de Janeiro State University (Brazil), \\ $* * * * * * *$ Oswaldo Cruz Foundation (Brazil)
}

\begin{abstract}
The purpose of the present study was to compare the blood pressure, heart rate, and rate pressure product behavior during interval and continuous aerobic exercise in physically active women. Eight physically active women with prior indoor cycling experience were recruited for the present study. Participants visited the laboratory for three sessions, the first visit was used for familiarization and the remaining two visits were to perform the experimental protocols in a randomized order: 1) Twenty-one minutes of continuous indoor cycling at $70 \%$ of maximum heart rate (CONT), and 2) Twenty-one minutes of inter val indoor cycling, alternating one minute at $90 \%$ and two minutes at $60 \%$ of maximum heart rate (INT). To assess the hemodynamic behavior, blood pressure, heart rate, and rate pressure product were also measuring at 6-minute (During-6), 12-minute (During-12), 18-minute (During-18), and 21-minute (During-21) intervals. Both protocols (continuous and interval) showed significant increases in blood pressure, heart rate, and rate pressure product in three out of four moments (During-6, During-12, and During-21), with the interval protocol showing higher values compared to the continuous protocol. The results of this study have practical implications for both prescription and cardiac rehabilitation and may be used in an athletic and non-athletic population, since a hypotension effect and lower cardiac workload is advantageous to one's fitness.
\end{abstract}

Key-words: aerobic training, autonomic response, cardiovascular physiology, hemodynamic response, physical exercise.

Resumen. El propósito del presente estudio fue comparar lo comportamiento de la presión arterial, la frecuencia cardíaca y doble producto durante el ejercicio aeróbico continuo y a intervalos en mujeres físicamente activas. Para el presente estudio se reclutaron ocho mujeres físicamente activas con experiencia previa en ciclismo indoor. Los participantes visitaron el laboratorio durante tres sesiones, la primera visita se utilizó para familiarizarse y les das visitas restantes fueron para realizar los protocolos experimentales en un orden aleatorio: 1) Veintiún minutos de ciclismo indoor continuo al 70\% de la frecuencia cardíaca máxima (CONT), y 2) Veintiún minutos de ciclismo indoor a intervalos, alternando un minuto al 90\% y dos minutos al 60\% de la frecuencia cardíaca máxima (INT). Para evaluar el comportamiento de la presión arterial, la frecuencia cardíaca y doble producto también se midieron a los 6 minutos (Durante-6), 12 minutos (Durante-12), 18 minutos (Durante-18) y 21 minutos (durante-21) durante la actividad. Ambos los protocolos (CONT y INT) mostraron aumentos significativos en la presión arterial, la frecuencia cardíaca, y el doble producto en tres de cuatro momentos (Durante-6, Durante-12 y durante-21), con el protocolo INT que muestra los valores más altos en comparación al protocolo CONT. Los resultados de este estudio tienen implicaciones prácticas tanto para la prescripción médica como para la rehabilitación cardíaca y pueden usarse en una población atlética y no atlética, ya que un efecto de hipotensión y una menor carga de trabajo cardíaco son ventajosos para la aptitud física.

Palabras clave: entrenamiento aeróbico, ejercicio físico, fisiología cardiovascular, respuesta autonómica, respuesta hemodinámica.

\section{Introduction}

Currently, physical activity is supported as a nonpharmacological intervention with the potential to promote prophylaxis and treatment of several chronic clinical conditions (e.g., hypertension) (Adami et al., 2010; Nunan et al., 2013; Mosquera et al., 2021). Physical activity is already recommended in this sense

Fecha recepción: 11-03-21. Fecha de aceptación: 03-08-21 Estêvão Rios Monteiro profestevaomonteiro@gmail.com of long (Pescatello et al., 2004), global recommendations have been updating exercise discourse in order to increase the recommended amount of weekly physical activity, taking into account the interaction between volume and intensity (Bull et al., 2020).

In this context, hypertension is a chronic disease with higher worldwide prevalence (Unger et al., 2020), with a high quantitative value regardless of age (Corrêa Neto et al., 2014). Thus, non-pharmacological strategies have been investigated as alternatives for their treatment. Respiratory and transcendental meditation techniques have been indicated as effective interventions to redu- 
ce blood pressure (Brook et al., 2015). Additionally, passive static stretching has shown important results in reducing and controlling hemodynamic and autonomic responses (de Araujo et al., 2018; 2019). The previous literature highlights physical activity, both aerobic and strength exercises, as controllers of blood pressure values (Pescatello et al., 2019; Souza et al., 2019), with aerobic exercise as a priority in this sense (Brook et al., 2015; Pescatello et al., 2015; Wen et al., 2017).

Forjaz et al. (1998) observed the behavior of blood pressure after two sessions of continuous aerobic training performed at $50 \%$ of $\mathrm{VO}_{2}$ peak with different volumes. Authors observed significant reductions in blood pressure for both protocols. Currently, interval aerobic training intersperses periods of high intensity with periods of low intensity (recovery) and has been investigated in relation to blood pressure responses. Pimenta et al. (2019) submitted their participants to two different protocols (continuous: 35-minute volume with intensity duration between $70 \%$ and $80 \%$ of $\mathrm{VO}_{2}$ reserve; interval: 30-minute volume with alternating 3 -minute intensity between $85 \%$ and $95 \%$ of the $\mathrm{VO}_{2}$ of reserve, and two minutes with intensity between 50\% and $60 \%$ of the $\mathrm{VO}_{2}$ reserve (recovery)). Both protocols significantly reduced post-exercise blood pressure with greater magnitude for the interval protocol. Similar results have already been highlighted by Angadi et al. (2015), where the authors observed post-exercise hypotension with greater magnitude for interval training when compared to continuous training. Although highintensity interval training appears to reduce postexercise blood pressure values, further studies should be performed before its recommendation, especially in individuals with hypertension (Ferrari et al., 2020) for their security during exercise (Corrêa Neto, 2015).

The rate pressure product is a noninvasive prediction of myocardial workload because it is directly related to the oxygen consumption of the heart muscle (Gobel et al., 1978; Ansari et al., 2012). Although previous investigations have observed the post-exercise blood pressure response in different study designs which compare continuous and interval training, no study has compared hemodynamic responses during the performance of these two training methods. Therefore, the purpose of the present study was to compare the blood pressure, heart rate, and rate pressure product behavior during interval and continuous aerobic exercise in physically active women. The hypothesis of the present study is that the interval training session will cause a higher magnitude to increase in the cardiovascular responses when compared to the continuous training session.

\section{Methods}

\section{Ethical aspects}

The present research followed all procedures of research ethics for human studies. The procedures of the present study were carried out in accordance with Resolution No. 466/12 of the National Health Council. This work was conducted in accordance with the Declaration of Helsinki. Prior to the study all participants were provided verbal explanation about all procedures, and they read and signed an informed consent document.

\section{Participants}

Participants were recruited based on a priori sample size calculation (Beck, 2013). To calculate the sample size, the G*Power (V. 3.1) software was used (Faul et al., 2007). The calculation considered an effect size $=$ $0.45, \alpha=5 \%, 1-\beta=0.80$, and non-sphericity correction $=1.0$. Systolic blood pressure baseline values, the sample size calculation, indicated that 8 participants were sufficient to investigate the question posed. Eight physically active women (Age: 29.00 (25.75 - 36.75) years; Height: $1.61(1.51-1.64) \mathrm{m}$; Weight: $69.60(61.25$ - 85.75) kg; Body Mass Index: 26.65 (23.67 $-31.60) \mathrm{kg} / \mathrm{m} 2$ ) with prior experience in indoor cycling exercise ( $\geq 6$ months) were recruited by convenience for the present study.

The following exclusion criteria were adopted: (a) medical condition that could influence the test results (e.g., cardiovascular disease). (b) use any type of drugs that could influence the test results (e.g., caffeine, ergogenic, and soothing consumption). (d) functional limitations or medical conditions that could have compromised their health or confounded the study results. (e) to avoid any intense physical activity during the experimental procedures. Participants answered an anamnesis where their profiles were characterized, meeting or not the inclusion criteria of this study. They also answered the Physical Activity Readiness Questionnaire (PAR-Q), which is a proposal for preparticipatory screening for partially effective physical activity practice (Andreazzi et al., 2016). Thus, all participants must necessarily respond negatively to the PAR-Q to be included in this study. All participants were instructed to maintain their eating habits throughout the seven-day period of the research. Anthropometric data were obtained using standard procedures: body mass 
(Techline BAL - 150 digital scale, São Paulo, Brazil) and height (Stadiometer ES 2030 Sanny, São Paulo, Brazil).

\section{Procedure}

A counter-balanced, randomized (Latin Square format), cross-over, and within-subject experimental design was used to compare the effects of different aerobic exercises (interval vs continuous) on blood pressure, heart rate, and rate pressure product. Participants visited the laboratory for three sessions during a seven-day period with at least forty-eight hours between visits. The first session was used to familiarize the participants with all procedures and collect the anthropometric data while experimental protocols were performed during the remaining two sessions. Sessions two and three were used to perform the experimental protocols in a randomized order: 1)Twenty-one minutes of continuous indoor cycling at $70 \%$ of maximum heart rate (CONT), and e) Twenty-one minutes of interval indoor cycling alternating one minute at $90 \%$ and two minutes at $60 \%$ of maximum heart rate (INT). All procedures were performed at the same time of day (during the morning hours) for a given participant in order to minimize any potential circadian effects. Baseline values were measured after 10-minute of an absolute rest in a quiet room. To assess the hemodynamic behavior, on blood pressure, heart rate, and rate pressure product were also measures at 6-minute (During-6), 12-minute (During-12), 18-minute (During-18), and 21 minute (During-21) during intervention (Figure 1). These times were intentionally chosen in order to equalize the measurement moments between the protocols. The maximum heart rate was estimated using the formula: 220-age (Karvonen et al., 1957).

\section{Instruments}

Blood pressure: Systolic blood pressure was measured

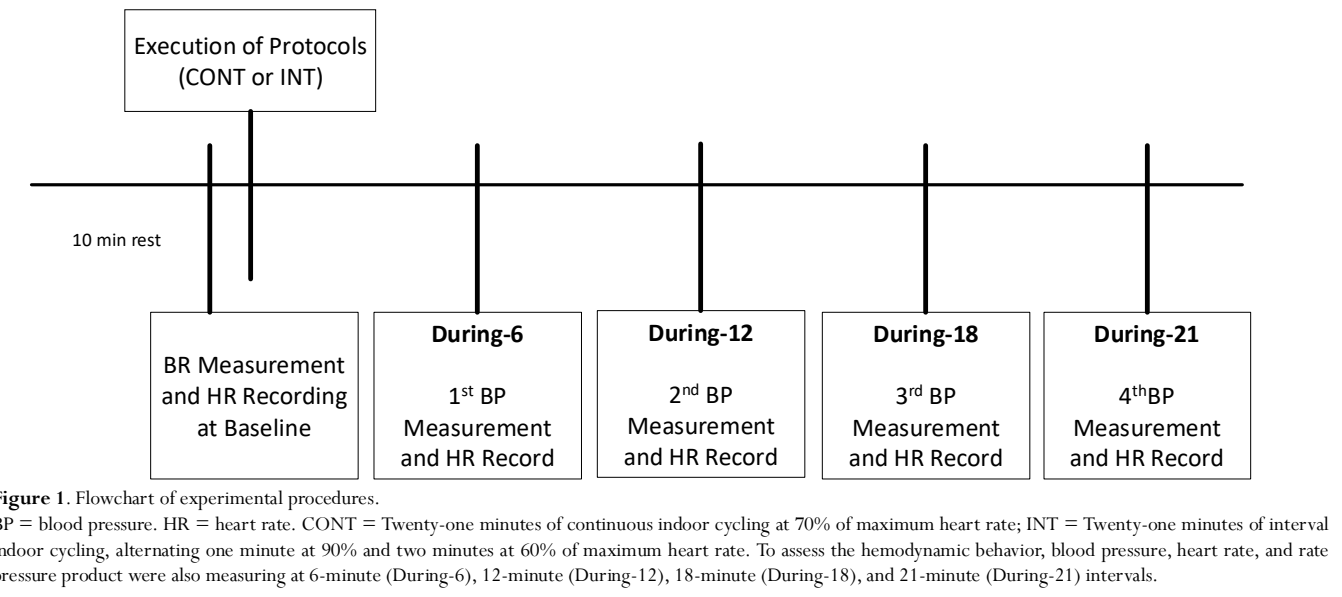

using an automatic oscillometric device (Omron Hem 7113, São Paulo, Brazil) (Parameswarppa \& Narayana, 2015). During each experimental session, systolic blood pressures was assessed after 10-minute passive rest period on arrival at the laboratory and at During-6, During-12, During-18, and During-21 during intervention. Measurements were performed in a seated position on the left arm consistent with the recommendations of the International Society of Hypertension (Unger et al., 2020).

Heart rate: During each experimental session, heart rate was assessed after 10-minute passive rest period on arrival at the laboratory and at During-6, During12, During-18, and During-21 during intervention. A heart rate monitor was fixed using an elastic belt to the lower third on the sternum (xiphoid process). The data were simultaneously transmitted to and stored in a watch (Polar RS800cx; Kempele, Finland).

Rate pressure product: Rate pressure product was calculated by the equation: Heart Rate $\left(\right.$ beats $\min ^{-1}$ ) $\mathrm{x}$ systolic blood pressure $(\mathrm{mmHg})$. It represents the workload or oxygen demand of the heart and reflects the hemodynamic stress (Ansari et al., 2012).

\section{Statistical analyses}

Data normality was tested using a method suggested by Chan (2003). First, the Shapiro-Wilks test was used to analysis the data normality, then the Kurtosis, histograms and Q-Q plots were used to visually check the data distribution. Normality of the data was rejected, and non-parametric tests were used. Friedman nonparametric test was used to determine the effects of the different experimental conditions on the dependent variables. If the null hypothesis was rejected, pairwise comparisons were performed with a Bonferroni correction for multiple comparisons. Median was used as a measure of central tendency. Wilcoxon test was applied for each moment throughout inter-group comparison. Interquartile range was determined as a measure of descriptive statistics dispersion, $\mathrm{w}$ h $\mathrm{i} \quad \mathrm{c} \quad \mathrm{h}$ 
indicates the variability of results. Interquartile range was calculated based on dividing a data set into quartiles and subtracted the third quartile (upper limits) by the first quartile (lower limits). Effect size values at each time point in relation to rest were calculated in all protocols and for all variables. The calculation and classification followed the Pallant (2016) recommendations for the effect size for non-parametric distributions. For this purpose, the effect size was calculated through the ratio $\mathrm{z}$ value by the square root of the number of observations and for classification the cutoff suggested by Cohen (1988) were used as small $(0.10-0.29)$, moderate $(0.3-0.49)$, and large $(0.5-$ 1.0). All analyses were performed using SPSS version 21 (SPSS Inc., Chicago, IL, USA) with an alpha level of 0.05 .

\section{Results}

There were no statistically significant differences among baseline measures between protocols for blood pressure, heart rate, and rate pressure product. Significant increases in systolic blood pressure values were observed throughout the CONT protocol at During-6 ( $\mathrm{p}=0.005)$, During-12 ( $=0.030)$, and During-21 ( $\mathrm{p}=0.040)$ when compared to baseline (Table 2). Similar results were observed for the INT protocol, where significant increases in systolic blood pressure values were found at During-6 $(\mathrm{p}=0.010)$, During-12 ( $\mathrm{p}=0.04)$, and During-21 $(\mathrm{p}=0.001)$ when compared to baseline (Table 1).

Table 2 shows the heart rate values for each moment and protocol. Significant increases in heart rate values were observed in CONT protocol at During-6 ( $\mathrm{p}=$ 0.003), During-12 ( $\mathrm{p}=0.010)$, and During-21 $(\mathrm{p}=$ 0.005). Additionally, INT protocol shows significant increases in all moments at During-6- $(\mathrm{p}=0.010)$, During-12 ( $=0.004)$, During-18 ( $\mathrm{p}=0.020)$, and During-21 ( $\mathrm{p}=0.040)$. In the inter-protocol comparison, significant differences occurred at all moments $(p<0.05)$.

Significant increases in rate pressure product were observed throughout the CONT protocol at During-6 $(\mathrm{p}=0.009)$, During-12 $(\mathrm{p}=0.009)$, During-18 $(\mathrm{p}=$ 0.020 , and During-21 ( $\mathrm{p}=0.020)$ when compared to baseline (Table 4). Similarly, INT protocol showed a significant increase at During-6 $(\mathrm{p}=0.009)$, During-12 $(p=0.020)$, and During-21 ( $=0.001)$ (Table 3). When comparing the rate pressure product between protocols, significant differences were found for all moments $(\mathrm{p}<$ 0.05), except at During-18 (Table 3).

\section{Discussion}

The purpose of the present study was to analyze the blood pressure, heart rate, and rate pressure product behavior during interval and continuous aerobic exercise in physically active women. Both protocols (continuous and interval) showed significant increases in blood pressure, heart rate, and rate pressure product in at

Table 1.

Systolic blood pressure values for each protocol and moments (median and interquartile range).

\begin{tabular}{lcccccc} 
& Baseline & During-6 & During-12 & During-18 & During-21 & Intra-protocol p-value \\
\hline CONT & $121.5(113.25-132.0)$ & $244.5(196.75-258.75)^{*}$ & $224.5(207.5-256.75)^{*}$ & $218.5(187.25-263.75)$ & $214.5(173.75-259.25)^{*}$ & 0.002 \\
Effect size & & 0.86 Large & 0.9 Large & 0.67 Large & 0.71 Large \\
INT & $124.5(116.5-134.0)$ & $257.0(226.5-265.0)^{*}$ & $234.0(196.75-260.75)^{*}$ & $240.5(185.5-260.25)$ & $269.5(246.25-278.5)^{*}$ \\
Effect size & & 0.81 Large & 0.71 Large & 0.57 Large & 1.00 Large \\
Inter-protocol p-value & 0.326 & 0.362 & 0.889 & 0.674 & 0.093 \\
\hline
\end{tabular}

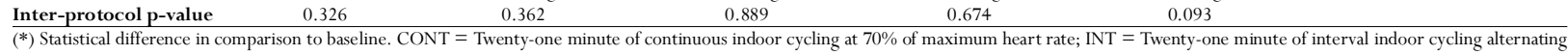
1 minute at $90 \%$ and two minutes at $60 \%$ of maximum heart rate. During-6 - 6-minute during intervention; During-12 - 12-minute during intervention; During-18 - 18 -minute during intervention; During21 - 21-minute during intervention.

Table 2.

Heart rate values for each protocol and moments (median and interquartile range).

\begin{tabular}{|c|c|c|c|c|c|c|}
\hline & Baseline & During-6 & During-12 & During-18 & During-21 & Intra-protocol p-value \\
\hline$\overline{\text { CONT }}$ & $85.0(70.25-90.75)$ & $131.5(128.5-137.0)^{*}$ & $132.5(128.5-135.75)^{*}$ & $130.0(125.5-134.5)$ & $133.5(130.0-135.0)^{*}$ & 0.001 \\
\hline Effect size & & 0.90 Large & 0.79 Large & 0.59 Large & 0.86 Large & \\
\hline INT & $81.0(70.75-81.75)$ & $166.0(159.75-172.5)^{* \#}$ & $168.0(160.25-171.25)^{* \#}$ & $165.5(153.0-173.75)^{* \#}$ & $166.5(157.0-170.75)^{* \#}$ & 0.002 \\
\hline Effect size & & 0.79 Large & 0.88 Large & 0.77 Large & 0.71 Large & \\
\hline Inter-protocol p-value & 0.362 & 0.012 & 0.012 & 0.012 & $0.012^{\circ}$ & \\
\hline
\end{tabular}

(*) Statistical difference in comparison to baseline $\left(^{\#}\right)$ Statistical difference to CONT. CONT = Twenty-one minute of continuous indoor cycling at $70 \%$ of maximum heart rate; INT $=$ Twenty-one minute of interval indoor cycling alternating 1 minute at $90 \%$ and two minutes at $60 \%$ of maximum heart rate. During-6 - 6-minute during intervention; During-12 - 12 -minute during intervention; During-18 - 18 minute during intervention; During-21 - 21 -minute during intervention.

Table 3.

$\begin{array}{cccc}\text { Rate pressure product values for each protocol and each moment (median and interquartile range). } & \text { During-6 } & \text { During-12 } & \text { During-18 }\end{array}$

\begin{tabular}{|c|c|c|c|c|c|c|}
\hline & & & & & & \\
\hline CONT & $10211.5(7950.0-11954.25)$ & $32310.0(26427.75-33672.75)^{*}$ & $29000.0(28148.0-33678.75)^{*}$ & $28405.0(22799.0-34105.5)^{*}$ & $28721.0(22998.75-34939.75)^{*}$ & 0.003 \\
\hline Effect size & & 0.83 Large & 0.83 Large & 0.50 Large & 0.50 Large & \\
\hline
\end{tabular}

$\begin{array}{llllllll}\text { INT } & 10019.5(8858.5-10854.0) & 43251.5(36439.75-43818.75)^{* \#} & 38505.0(32762.5-44735.25)^{* \#} & 40805.5(29355.25-42730.5)^{\#} & 44148.0(41668.5-46050.0)^{* \#} & 0.001\end{array}$

$\begin{array}{lccccc}\text { Effect size } & & 0.83 \text { Large } & 0.75 \text { Large } & 0.55 \text { Large } & 1.00 \text { Large } \\ \text { Inter-protocol } & 0.674 & 0.025 & 0.025 & 0.069 & 0.017\end{array}$

p-value $(*)$ Statistical difference in comparison to baseline $\left(^{\#}\right)$ Statistical difference to CONT. CONT = Twenty-one minute of continuous indoor cycling at $70 \%$ of maximum heart rate; INT = Twenty-one minute of
interval indoor cycling alternating 1 minute at $90 \%$ and two minutes at $60 \%$ of maximum heart rate. During-6 - 6-minute during intervention; During-12 - 12 -minute during intervention; During- 18 - 18 minute during intervention; During-21 - 21 -minute during intervention. 
least three moments (During-6, During-12, and During21), with the interval protocol showing higher values compared to the continuous protocol. Hemodynamic behavior followed the standards expected for healthy individuals during the performance of an aerobic effort, with significant increases in systolic blood pressure, heart rate, and consequently in the rate pressure product (Green et al., 2017). The result highlighted in the present study is the inter-protocol comparison, where the INT protocol presented increases with greater magnitude in comparison to the CONT protocol.

The literature indicates several cardiovascular benefits after performing high-intensity interval training, from molecular effects (Schmitz et al., 2017) to blood pressure control, such as increase in nitric oxide release, reduction in vasoconstriction and increase in shear force (Delgado-Floody et al., 2020). Wewege (2018) reinforce the hypothesis related to safety when performing high-intensity interval exercises, indicating a low number of adverse cardiovascular events; however, it is worth highlighting a risk-benefit relationship within the cardiovascular parameters. Corrêa Neto (2015) corroborates that the risk-benefit ratio would focus on enabling the greatest benefits after performing the exercise or training, with strategies that enable the lowest risks during the execution of the effort, according to present study results, considering the method when prescribing aerobic training may be important with regard to this condition. Even as the results in favor of HIIT on the benefits in the blood pressure are not consensual. Serna et al. (2019) observed that after eight weeks of continuous aerobic training with moderate intensity and innervated form with high intensity, the moderate and continuous effort group obtained more significant improvements in relation to tension levels. Still, Forjaz et al. (1998), in a classic study, demonstrated that continuous low-intensity aerobic exercise was efficient in providing reductions in blood pressure which would be related to reduced sympathetic activity as well as the vasodilator effect of local metabolites.

Wewege et al. (2018) systematics' review indicated a low cardiovascular risk with high-intensive interval training in patients undergoing cardiac rehabilitation, but authors did not describe the absolute values of the cardiovascular system (e.g., autonomic and hemodynamic values). Therefore, even with a low number of adverse events, it is not possible to observe the magnitude of response of these variables. It is important to highlight that in exercise programs for cardiac rehabilitation, recommended intensity ranges varying between $40 \%$ and $85 \%$ of the reserve heart rate (Kim et al., 2019); thus, the intensity range of the present study denotes less cardiovascular overload during its execution, meeting the recommendations of Kim et al. (2019). Even Powell et al. (2018) indicated no advantages, neither in relation to mortality nor in the number of hospitalizations for patients after cardiocirculatory events that included physical exercises in their rehabilitation routine when compared to those that did not.

Additionally, Schmitz et al. (2017) observed that highintensity interval training increased circulating levels of miR-222 and miR-29, which are important modulators of cardiac growth acting protectively in cardiac remodeling with a pathological characteristic. However, this study did not control the intensity of the effort in its protocols. The sample group should have run at the highest possible speed, considering the influence of everyone, the perception of effort may have varied widely. This allows us to hypothesize that varying levels of effort denote the protective effect of exercise, considering that this type of adaptation should be tested in lower intensity exercises (less cardiac overload).

The present study found a significantly larger rate pressure product in the INT protocol compared to the CONT protocol; this difference was caused by greater increases in heart rate during the execution of the INT. The rate pressure product is a noninvasive prediction of myocardial workload because it is directly related to the oxygen consumption of the heart muscle (Gobel et al., 1978; Ansari et al., 2012). Individuals who achieve rate pressure product values above 30.000 on exercise testing seem to have a good prognosis for obstructive coronary disease (Fornitano and Godoy, 2006). However, for individuals with angina, the rate pressure product of 30.000 may be a cut-off risk point. In this study, the INT protocol elicited rate pressure product values above 30.000 in all measurement times. Thus, it is necessary to analyze the risk-benefit before choosing high-intensity training with regard to cardiovascular benefits to exercise, given that light intensity exercises promote hemodynamic increases of lesser magnitude.

\section{Limitations}

All participants were female as such it is worth highlighting that there was no control or monitoring of the menstrual cycle, as were there no control regarding the use of contraceptive drugs. However, the use of contraceptives drugs as the differences in menstrual 
cycle (female physiology) did not significantly modify the hemodynamic values (e.g., blood pressure), since they have refined homeostatic control mechanisms, which normalize the potential changes. (Oifang et al., 1994; Arifuddin et al., 2012).

\section{Conclusion}

In conclusion, high-intensity interval exercise showed greater cardiovascular stress when compared to continuous low-intensity exercise. Thus, before choosing which protocol should be prescribed, considering the safety of cardiovascular responses, it seems that for specific groups such as cardiac and hypertensive patients, continuous exercises of lower intensity can promote less exposure to risks. Anyway, future studies with investigations in this direction are recommended, especially with specific groups of patients with heart disease and hypertension, to corroborate the extrapolation power of the results.

\section{References}

Adami, P. E., Negro, A., Lala, N., Martelletti, P. (2010). The role of physical activity in the prevention and treatment of chronic diseases. La Clinica Terapeutica, 161(6), 537-541.

Andreazzi, I. M., Takenaka,V. S., Silva, P. B. S. B., Araújo, M. P. (2016). Pre-Sports Participation Examination and the PAR-Q in Gym Users. Revista Brasileira de Medicina do Esporte, 22(4), 272-276. doi:10.1590/1517869220162204158121.

Angadi, S. S., Bhammar, D. M., Gaesser, G. A. (2015). Postexercise Hypotension After Continuous, Aerobic Interval, and Sprint Interval Exercise. Journal of Strength and Conditioning Research, 29(10), 2888 2893. https:// doi.org/ 10.1519/JSC.0000000000000939.

Ansari, M., Javadi, H., Pourbehi, M., Mogharrabi, M., Rayzan, M., Semnani, S., Jallalat, S., Amini, A., Abbaszadeh, M., Barekat, M., Nabipour, I., Assadi, M. (2012). The association of rate pressure product (RPP) and myocardial perfusion imaging (MPI) findings: A preliminary study. Perfusion, 27(3), 207-213. https:/ / doi.org/10.1177/0267659112436631.

Arifuddin, M. S., Hazari, M. A. H., Reddy, B. R. (2012). Blood pressure variations during different phases of menstrual cycle. International Journal of Science and Nature, 3(3), 551-554.

Beck, T.W. (2013). The importance of a priori sample size estimation in strength and conditioning research. Journal of Strength and Conditioning Research, 27(8): 2323-2337. https://doi.org/10.1519/JSC.0b013e318278eea0.

Bull, F. C., Al-Ansari, S. S., Biddle, S., Borodulin, K., Buman, M. P., Cardon, G., et al. (2020). World Health Organization 2020 guidelines on physical activity and sedentary behaviour. British Journal of Sports Medicine, 54(24), 1451 62. http://dx.doi.org/10.1136/bjsports2020-102955.

Brook, R. D., Jackson, E. A., Giorgini, P., McGowan, C. L. (2015) When and How to Recommend 'Alternative Approaches' in the Management of High Blood Pressure. The American Journal of Medicine, 128(6), 567570 . https:/ /doi.org/10.1016/j.amjmed.2014.12.029.

Chan, Y. H. (2003). Bioestatistics 101: data presentation. Singapore Medical Journal, 44(6), 280-285.

Cohen, J. (1988). Statistical power analysis for the behavioral sciences ( $2^{\mathrm{a}}$ ed.). New York: Lawrence Erlbaum Pub.

Corrêa Neto, V. G., Sperandei, S., Silva, L. A. I., Maranhão Neto, G. de A., Palma, A. (2014). Arterial hypertension among adolescents in Rio de Janeiro: prevalence and Association with physical activity and obesity. Ciência $e$ SaúdeColetiva, 19(6), 1699708.https://doi.org/10.1590/ 1413-81232014196.05262013.

Corrêa Neto, V. G. (2015). Intervening variables associated with of strength training prescription and the responses of blood pressure: a review of the risk-benefit ratio in the development of training sessions. Arquivos em Movimento, 11(2), 47-55.

Delgado-Floody, P., Izquierdo, M., Ramírez-Vélez, R., Caamaño-Navarrete, F., Moris, R., Jerez-Mayorga, D., et al. (2020). Effect of High-Intensity Interval Training on Body Composition, Cardiorespiratory Fitness, Blood Pressure, and Substrate Utilization During Exercise Among Prehypertensive and Hypertensive Patients With Excessive Adiposity. Frontiers in Physiology, 11:558910. https://doi.org/10.3389/ fphys. 2020.558910.

Faul F, Edfelder E, Lang A-G, and Buchner A. (2007). G*Power 3: A flexible statistical power analysis program for the social, behavioral, and biomedical sciences. Behavior Research Methods, 39: 175-191. https:/ /doi.org/10.3758/bf03193146.

Felipe, P.N. C., Oliveira, A.A. R., Barbosa, M. S., Napoleão, C. M., Nobre, M. M. A., Alves, I. A. A. (2018). The use of double product as a subjective marker of resistance exercise exertion for hypertensive patients. Motricidade, 14(1), 87-90.

Ferrari, F., Martins, V.M. (2020). High-intensity Interval Training versus Continuous Exercise: Is There a Difference Regarding the Magnitude of Blood Pressure 
Reduction? Arquivos Brasileiros de Cardiologia, 115(1), 15 16. https:/ / doi.org/10.36660/abc.20200261

Forjaz, C. L. de M., Santaella, D. F., Rezende, L. O., Barretto, A. C. P., Negrão, C. E. (1998). Exercise duration determines the magnitude and duration of post-exercise hypotension. Arquivos Brasileiros de Cardiologia, 70(2), 99 104. https: / / doi.org/10.1590/S0066782 X1998000200006.

Fornitano, L. D., Godoy, M. F. (2006). Increased rate-pressure product as predictor for the absence of significant obstructive coronary artery disease in patients with positive exercise test. Arquivos Brasileiros de Cardiologia, 86(2), 138-144. https://doi.org/10.1590/s0066$782 \times 2006000200010$.

Green, D. J., Hopman, M.T. E., Padilla, J., Laughlin, M. H., Thijssen, D. H. J. (2017). Vascular Adaptation to Exercise in Humans: Role of Hemodynamic Stimuli. Physiological Reviews, 97(2), 495-528. https://doi.org/10.1152/ physrev.00014.2016.

Gobel, F. L., Norstrom, L. A., Nelson, R. R., Jorgensen, C. R., Wang, Y. (1978). The rate-pressure product as an index of myocardial oxygen consumption during exercise in patients with angina pectoris. Circulation, 57(3), 549 56. https: //doi.org/10.1161/01.cir.57.3.549.

Karvonen, M. J., Kentala, E. Mustala, O. (1957). The effects of training on heart rate: a longitudinal study. Ann Med Exper Fenn, 35(3), 307-315.

Kim, C., Sung, J., Lee, J. H., Kim, W. S., Lee, G. J., Jee, S., et al. (2019). Clinical practice guideline for cardiac rehabilitation in Korea: recommendations for cardiac rehabilitation and secondary prevention after acute coronary syndrome. Korean Circulation Journal, 49(11), 1066-1111. https://doi.org/10.4070/kcj.2019.0194.

Mosquera, J. C. G., Vargas, L. F. A. (2021). Sedentarismo, actividad física y salud: uma revision narrativa. Retos, 42, 478-499.

Nunan, D., Mahtani, K. R., Roberts, N., Heneghan, C. (2013). Physical activity for the prevention and treatment of major chronic disease: an overview of systematic reviews. Systematic Reviews, 2(1), 56. https://doi.org/ 10.1186/2046-4053-2-56.

Parameswarppa, S. B., Narayana, J. (2015). Impact of noise hearing and hypertension among works in steel industry. International Journal of Current Microbiology Applied Sciences, 4(1), 124-133.

Pescatello, L. S., Buchner, D. M., Jakicic, J. M., Powell, K. E., Kraus, W. E., Bloodgood, B., et al. (2019) Physical activity to prevent and treat hypertension: a systematic review. Medicine \& Science in Sports \& Exercise, 51(6), 1314 1323 .https: / / doi .org/ 10 . 1249 / MSS.0000000000001943.
Pallant, J. (2016). SPSS Survival Manual: a step by step guide to data analysis using IBM SPSS. 6 edição , Mc Graw Hill Education, Nova York.

Pescatello, L. S., Franklin, B. A., Fagard, R., Farquhar, W. B., Kelley, G. A., Ray, C. A. (2004). Exercise and Hypertension. Medicine \& Science in Sports \& Exercise, 36(3), $53353 . \quad$ https://doi.org/10.1249/ 01.mss.0000115224.88514.3a.

Pimenta, F. C., Montrezol, F. T., Dourado, V. Z., da Silva, L. F. M., Borba, G. A., de Oliveira Vieira,W., et al. (2019). High-intensity interval exercise promotes post-exercise hypotension of greater magnitude compared to moderate-intensity continuous exercise. European Journal ofApplied Physiology, 119(5), 1235 1243.https:/ / doi.org/ 10.1007/s00421-019-04114-9.

Powell, R., McGregor, G., Ennis, S., Kimani, P. K., Underwood, M. (2018). Is exercise-based cardiac rehabilitation effective? A systematic review and metaanalysis to re-examine the evidence. BMJ Open, 8(3), e019656. https://doi.org/10.1136/bmjopen-2017019656

Qifang, S., Xiurong, J., Haifang, L., Zhongshu, Z. (1994). Blood pressure changes and hormonal contraceptives. Contraception, 50, 131-141.

Schmitz, B., Rolfes, F., Schelleckes, K., Mewes, M., Thorwesten, L., Krüger, M., etal. (2018). Longer work/ rest intervals during high-intensity interval training (HIIT) lead to elevated levels of miR-222 and miR-29c. Frontiers in Physiology, 9:395. https:/ / doi.org/10.3389/ fphys.2018.00395.

Serna, V. H. A., Feito, Y., Villada, F. A. P., Romero, A. V. V., Veles, E. F. A. (2019). Effects of high-intensity interval training compared to moderate-intensity continuous training on maximal oxygen consumption and blood pressure in healthy men: A randomized controlled trial. Biomedica, 39(3), 524-536. doi:10.7705/ biomedica. 4451

Unger,T., Borghi, C., Charchar, F., Khan, N. A., Poulter, N. R., Prabhakaran, D., et al. (2020). International Society of Hypertension global hypertension practice guidelines. Journal of Hypertension, 38(6), 982 1004. https: / / doi.org/ 10.1161/HYPERTENSIONAHA.120.15026.

Wen, H., Wang, L. (2017). Reducing effect of aerobic exercise on blood pressure of essential hypertensive patients:A meta-analysis. Medicine, 96(11), e6150.https:/ /doi.org/10.1097/MD.0000000000006150.

Wewege, M. A., Ahn, D., Yu, J., Liou, K., Keech, A. (2018). High intensity interval training for patients with cardiovascular disease - is it safe? a systematic review. Journal of the American Heart Association, 7 (21), e009305. https://doi.org/10.1161/JAHA.118.009305. 